University of Wollongong

Research Online

Australian Institute for Innovative Materials -

Papers

Australian Institute for Innovative Materials

$1-1-2019$

\title{
Plasma functionalisation of few-layer graphenes and carbon nanotubes for graphene microsupercapacitors
}

\author{
Emily Smith \\ University of Surrey \\ Yuqing Liu \\ Chris Stirling \\ Haydale Ltd. \\ David J. Watson \\ University of Surrey \\ Robert C.T. Slade \\ University of Surrey
}

University of Wollongong, yuqing@uow.edu.au

See next page for additional authors

Follow this and additional works at: https://ro.uow.edu.au/aiimpapers

Part of the Engineering Commons, and the Physical Sciences and Mathematics Commons

Research Online is the open access institutional repository for the University of Wollongong. For further information contact the UOW Library: research-pubs@uow.edu.au 


\title{
Plasma functionalisation of few-layer graphenes and carbon nanotubes for graphene microsupercapacitors
}

\author{
Abstract \\ Plasma processing, as a commercial and large-scale technology, was used to functionalize few-layer \\ graphene (FLG) and multi-walled carbon nanotubes (MWCNT). The successful functionalities of FLG and \\ MWCNT have been confirmed by elemental microanalysis, $X$-ray photoelectron spectroscopy, acid-base \\ titration and zeta potential measurements. With the assistance of poly(3,4-ethylenedioxythiophene)- \\ poly(styrenesulfonate) (PEDOT/PSS), a water-dispersible and conductive polymer, a composite of \\ functionalized FLG and MWCNT was fabricated into large-size flexible films and also interdigitated \\ microelectrodes for microsupercapacitor application via simple and scalable techniques (i.e. doctor \\ blading and laser-etching). When normalised by volume and area, the devices made from FLG(NH3)- \\ MWCNT(Acid) (19.9 F cm-3 at $5 \mathrm{mV} \mathrm{s}-1$ and $12.2 \mathrm{~F} \mathrm{~cm}-3$ at $200 \mathrm{mV} \mathrm{s}-1$ ) and FLG-MWCNT(Acid) (19.5 \\ $\mathrm{mF} \mathrm{cm}-2$ at $5 \mathrm{mV} \mathrm{s}-1$ and $12.8 \mathrm{mF} \mathrm{cm}-2$ at $200 \mathrm{mV} \mathrm{s}-1$ ) show the best performing composites, \\ respectively, indicating how effective functionalization of FLG and MWCNT is for the enhancement of \\ electrochemical capacitance. In-situ Raman microscopy confirmed the reversible pseudo-capacitive \\ behaviour of electrode materials and the stable electrochemical performance of the devices. The facile \\ techniques used in this work and the good device performances show their great potential for wearable \\ applications.

\section{Disciplines} \\ Engineering | Physical Sciences and Mathematics

\section{Publication Details} \\ Smith, E. A. M., Liu, Y., Stirling, C., Watson, D. J., Slade, R. C. T., Chen, J. \& Crean, C. (2019). Plasma \\ functionalisation of few-layer graphenes and carbon nanotubes for graphene microsupercapacitors. \\ Electrochimica Acta, 317 348-357.

\section{Authors} \\ Emily Smith, Yuqing Liu, Chris Stirling, David J. Watson, Robert C.T. Slade, Jun Chen, and Carol Crean
}




\title{
Plasma functionalisation of few-layer graphenes and carbon nanotubes for graphene microsupercapacitors
}

\author{
Emily A. M. Smith ${ }^{1}$, Yuqing Liu ${ }^{2}$, Chris Stirling ${ }^{3}$, David J. Watson ${ }^{4}$, Robert C. T. Slade ${ }^{4}$, \\ Jun Chen ${ }^{2}$ and Carol Crean ${ }^{*}$
}

1 Department of Mechanical Engineering Sciences, University of Surrey, GU2 7XH, United Kingdom

2 Intelligent Polymer Research Institute and ARC Centre of Excellence for Electromaterials Science, University of Wollongong, Wollongong, NSW 2500, Australia

3 Haydale Ltd., Clos Fferws, Parc Hendre, Capel Hendre, Ammanford, SA18 3BL, United Kingdom

4 Department of Chemistry, University of Surrey, GU2 7XH, United Kingdom

*c.crean@surrey.ac.uk

Electronic Supplementary Information (ESI) available

\begin{abstract}
Plasma processing, as a commercial and large-scale technology, was used to functionalize few-layer graphene (FLG) and multi-walled carbon nanotubes (MWCNT) in this work. The successful functionalities of FLG and MWCNT have been confirmed by elemental microanalysis, X-ray photoelectron spectroscopy, acid-base titration and zeta potential measurements. With the assistance of poly(3,4-ethylenedioxythiophene)-poly(styrenesulfonate) (PEDOT/PSS), a water-dispersible and conductive polymer, a composite of functionalized FLG and MWCNT was fabricated into large-size flexible films and also interdigitated microelectrodes for microsupercapacitor application via simple and scalable techniques (i.e. doctor blading and laser-etching). When normalised by volume and area, the device made from FLG(NH$)-M W C N T$ (Acid) $\left(19.9 \mathrm{~F} \mathrm{~cm}^{-3}\right.$ at $5 \mathrm{mV} \mathrm{s}^{-1}$ and $12.2 \mathrm{~F} \mathrm{~cm}^{-3}$ at $200 \mathrm{mV}$ $\mathrm{s}^{-1}$ ) and FLG-MWCNT(Acid) $\left(19.5 \mathrm{mF} \mathrm{cm}^{-2}\right.$ at $5 \mathrm{mV} \mathrm{s}^{-1}$ and $12.8 \mathrm{mF} \mathrm{cm}^{-2}$ at $\left.200 \mathrm{mV} \mathrm{s}^{-1}\right)$ show the best performing composites, respectively, indicating how effective functionalization of FLG and MWCNT is for the enhancement of electrochemical capacitance. In-situ Raman microscopy confirmed the reversible pseudo-capacitive behaviour of electrode materials and the stable electrochemical performance of the devices. The facile techniques used in this work and the good device performance show their great potential for wearable applications.
\end{abstract}




\section{Introduction}

Carbon nanomaterials such as graphene and carbon nanotubes (CNTs) have been widely explored for use in supercapacitor and microsupercapacitor $\left(\mu\right.$-SC) devices, in particular for flexible energy storage. ${ }^{1,2}$ The properties of these carbon allotropes, such as high surface area, superior electrical and thermal conductivity, low mass, and high tensile strength make them attractive for energy storage applications. Studies using graphene have typically focused on graphene oxide (GO), reduced graphene oxide (rGO) and their respective composites, due to their ease of processing and production of larger quantities compared to pristine graphene. In $\mu$-SC applications, the reported specific capacitances with GO and rGO-based materials are much lower than theoretically predicted due to the restacking of graphene sheets, which reduces surface area and retards ion transport. Hybrid composites of graphene and CNTs could provide an improved conductive system relative to GO/CNT counterparts by preventing the re-stacking of graphene flakes. ${ }^{3,4}$ The composite material of graphene and CNTs have been widely used as electrode materials because graphene can provide a large surface area and high conductivity in-plane and it is believed that CNTs link graphene agglomerates into a more conducting and networked structure, resulting in an optimised capacitive performance.

Fabrication of thin film electrodes for supercapacitors has been investigated using many different methods including chemical vapour deposition (CVD), ${ }^{5}$ layer-by-layer deposition ${ }^{6}$ and spray deposition. ${ }^{7}$ Using sequential CVD, a graphene-CNT microsupercapacitor device was developed by Lin et al. and showed specific capacitance values of $2.16 \mathrm{mF} \mathrm{cm}^{-2}$ in aqueous electrolytes. ${ }^{5}$ The device was manufactured with distinct few-layer graphene (FLG) and CNT carpet layers, separately grown by CVD on nickel substrates, using an $\mathrm{Fe} / \mathrm{Al}_{2} \mathrm{O}_{3}$ catalyst. Beidaghi et al. used photolithography and spray deposition techniques to fabricate a rGO-CNT electrode structure (mass ratio of 9-1, respectively) for $\mu$-SC devices. The introduction of CNTs into the graphene sheets gave an improvement in volumetric capacitance from 4.4 $\mathrm{F} \mathrm{cm}^{-3}(\mathrm{rGO} \mu-\mathrm{SC})$ to $6.1 \mathrm{~F} \mathrm{~cm}^{-3}(\mathrm{rGO}-\mathrm{CNT}-9-1 \mu-\mathrm{SC})$ at $10 \mathrm{mV} \mathrm{s}^{-1}$.

Plasma treatment has been shown to modify the surface functionalities of graphene and CNT materials and to increase dispersion. In addition, the presence of functional groups can lead to pseudo-capacitive responses thereby increasing the subsequent supercapacitor device specific capacitance. Amine surface functionalities, for instance, on graphene materials have been shown to improve supercapacitor performance by Lai et al. and ammonia plasma treatment was successfully carried out by Lin et al. to introduce these nitrogen functionalities. ${ }^{9,10}$ In contrast, the removal of functional groups from the surface of an largely oxygenated material, such as GO, would increase the conductivity and reduce cell resistance. Argon gas plasma has been shown to 'clean' a GO material's surface through the bombardment of argon ions into the chemisorbed/physisorbed functional groups at low pressure $\left(3 \times 10^{-1} \mathrm{~Pa}\right) .{ }^{11}$ Furthermore, an argon and hydrogen gas mixture is used in plasma treatment as a reducing agent and hydrogen gas has also been used effectively in heat treatments to reduce GO. ${ }^{12,13}$ Plasma functionalisation has been used on graphene materials for sandwiched supercapacitors but has yet to be established in microsupercapacitor electrode materials. ${ }^{14}$

Micropower devices, like $\mu$-SCs, are required due to the tendency of microelectronics development towards sustainable self-powered micro- or nanosystems. $\mu$-SCs can deliver a higher power and energy density than their sandwiched supercapacitor counterparts. ${ }^{15}$ It is difficult to fabricate $\mu$-SC devices from graphene and CNT materials in large-scale due to poor dispersibility, film formability and sophisticated patterning techniques. However, once a large, quality film is obtained, an interdigitated electrode design can simplify fabrication of $\mu$-SC devices in large-scale production because of the planar assembly. Interdigitated electrodes also have improved performance, with fast charge-discharge times and long cycle life, due to increased accessibility of the electrodes. ${ }^{16}$ One method of achieving large, quality films are to use flexible materials such as graphene, CNTs and conducting polymers. In summary, flexible devices tend to be fabricated by large-film manufacture followed by film treatment to give patterned, planar, interdigitated electrodes. Techniques that yield this architecture have included photolithography, ${ }^{17}$ laser-scribing, ${ }^{18} \mathrm{CO}_{2}$ laser irradiation ${ }^{19}$ and laser lithography. ${ }^{20}$ The electrodes must be mechanically robust to tolerate these intensive device fabrication methods. ${ }^{21}$ Mao et al. investigated the chemical oxidation of multi-walled CNTs (MWCNTs) and ultrasonication with GO; this was sprayed onto 
polyethylene terephthalate (PET) and an infrared laser was used to reduce GO and form the electrode pattern. Overall capacitance of the solid-state device was $46.6 \mathrm{~F} \mathrm{~cm}^{-3}$, but the process is lengthy because it took 30 min to laser treat a small area of GO. ${ }^{22}$ Liu et al. have developed a planar, interdigitated, patterned electrode design that produces $\mu$-SC devices with high areal and volumetric capacitance and high cycling stability, from rGO and poly(3,4-ethylenedioxythiophene)-poly(styrenesulfonate) (PEDOT/PSS). ${ }^{3}$ This method was also used in this study and an equivalent polymer gel electrolyte was applied. The solid-state electrolyte, polyvinyl alcohol-orthophosphoric acid $\left(\mathrm{PVA}-\mathrm{H}_{3} \mathrm{PO}_{4}\right)$, has been shown to yield stable performances in the $0-1 \mathrm{~V}$ range and can be used as a separator as well as an ionic electrolyte for sandwiched rGO devices. ${ }^{23}$

In this work, rGO was substituted with commercialized FLG and along with commercialized MWCNT, these materials were functionalized via a simple, large-scale and effective plasma technique developed by Haydale Ltd. Characterisation of the plasma functionalised materials was performed with elemental microanalysis, XPS, zeta potential measurements and acid-base titrations. With the assistance of commercialized PEDOT/PSS, large films were successfully prepared from the composite of graphene and MWCNT, after optimization. Then, the two-electrode $\mu$-SC devices were manufactured from facile laser-etching techniques. The device performance demonstrates the FLG and MWCNT materials underwent effective functionalization for improvement of specific capacitance and the simple manufacturing techniques show great potential for real application.

\section{Experimental section \\ Materials}

A commercially available FLG was processed in a Haydale Ltd. plasma reactor in argon gas (Ar), a mixture of hydrogen and argon gases $\left(\mathrm{H}_{2} / \mathrm{Ar}\right)$ and ammonia gas $\left(\mathrm{NH}_{3}\right)$. The ammonia gas treatments in this paper are low level treatments and Haydale Ltd. has the capability to increase the nitrogen content to much higher levels than presented. Haydale Ltd. provided MWCNT and MWCNT(Acid), the latter material had been plasma treated with an unsaturated carboxylic acid. PEDOT/PSS pellets were obtained from Agfa (Orgacon DRY). Polyvinyl alcohol (PVA) was obtained from Sigma-Aldrich and orthophosphoric acid $\left(\mathrm{H}_{3} \mathrm{PO}_{4}, 85 \%\right)$ was obtained from Chem-Supply. PET was used as the substrate (100 $\mu \mathrm{m}$ thickness).

\section{Preparation of PEDOT/PSS-FLG-MWCNT electrodes}

FLG and MWCNT, and the plasma treated counterparts, were temporary plasma treated with a Harrick Expanded Plasma Cleaner (PDC-002) for 5 mins in air plasma to enable greater dispersion in water. The solutions were tip sonicated with a Branson Digital Sonifier at $3 \mathrm{~W}$ for $15 \mathrm{~min}$ (4 s on, $4 \mathrm{~s}$ off). PEDOT/PSS was added to the solution to give $15 \mathrm{mg} \mathrm{cm}^{-3}$ of total active material and this was magnetically stirred overnight. The solution was tip sonicated again using the same parameters. The material ratio of PEDOT/PSS-FLG-MWCNT was 1:3:1. Polyethylene terephthalate (PET) was sputtercoated with gold $(\sim 200 \mathrm{~nm})$ to give a flexible current collector and the current collector was treated in ozone plasma for $5 \mathrm{~min}$ before coating. The solution was tape casted with a doctor-blade $(0.5 \mathrm{~mm}$ above substrate) across the gold-coated PET at $10 \mathrm{~mm} \mathrm{~s}^{-1}$ and dried on the bed at $60^{\circ} \mathrm{C}$. The coating was approximately $40 \mathrm{~cm}^{2}$ in area and $5-20 \mu \mathrm{m}$ in thickness.

\section{Fabrication of flexible, solid-state microsupercapacitor}

Interdigitated electrodes were patterned on films with a $10.6 \mu \mathrm{m} \mathrm{CO} 2$ laser (Universal PLS6MW MultiWavelength Laser Platform, $30 \mathrm{~W}$, spot size $\sim 25 \mu \mathrm{m}$ ). The gold contacts were connected to copper tape and Kapton ${ }^{\circledR}$ tape was used to prevent contact between adjacent electrodes. $\mathrm{A}_{3} \mathrm{PO}_{4} / \mathrm{PVA}$ gel electrolyte was prepared by heating a mixture of PVA powder $(4 \mathrm{~g}), \mathrm{H}_{3} \mathrm{PO}_{4}(6 \mathrm{~g})$ and deionized water $\left(40 \mathrm{~cm}^{3}\right)$ to $85^{\circ} \mathrm{C}$ with magnetic stirring until the solution became clear. Application of the $\mathrm{PVA} / \mathrm{H}_{3} \mathrm{PO}_{4}$ electrolyte (heated to $85^{\circ} \mathrm{C}$ prior to use, $0.50 \mathrm{~cm}^{3}$ ) was completed by drop casting the gel onto the interdigitated electrodes. Films were left to dry in standard atmospheric conditions overnight to allow water evaporation contained in the electrolyte. An additional layer of cold electrolyte $\left(0.25 \mathrm{~cm}^{3}\right)$ was applied on top, to ensure full coverage, and the devices were left to dry overnight again.

\section{Characterization}


Elemental microanalysis was carried out with a LECO CHNS-932 coupled with a LECO VTF-900 furnace by Instituto Nacional del Carbón (INCAR)/Consejo Superior de Investigaciones Científicas (CSIC). The X-ray photoelectron spectroscopy (XPS) measurements were made with a Theta Probe Angle-Resolved X-ray Photoelectron Spectrometer (ARXPS) System. The instrument uses a monochromatic source of $\mathrm{Al} \mathrm{K}$ radiation (photon energy $1486.6 \mathrm{eV}$ ) with an X-ray spot diameter of 400 $\mu \mathrm{m}$ and the analysis was carried out on powder samples, which were packed into stainless steel stubs. The spectra were processed using CasaXPS software and Shirley-type backgrounds were fitted. Zeta potential measurements were obtained by electrophoretic mobility measurements using a Nanosizer Nano ZS and aqueous solutions at $\mathrm{pH} 3, \mathrm{pH} 7$ and $\mathrm{pH} 11$ with concentrations of $0.4 \mathrm{~mol} \mathrm{dm}^{-3}$. Potentiometric measurements were obtained with a Mettler Toledo Autotitrator. A blank value was found with deionised water. The sample $(0.1 \mathrm{~g})$ was dispersed in deionised water $\left(100 \mathrm{~cm}^{3}\right)$ and sodium hydroxide $\left(1 \mathrm{~mol} \mathrm{dm}^{-}\right.$ ${ }^{3}$ ) was added by the Autotitrator. After stirring, the solution was then titrated with hydrochloric acid (1 mol $\mathrm{dm}^{-3}$ ) while the potential was measured. Typically, this produced two equivalence points (EQPs) on the titration curve, which previous literature has shown is indicative of multiple acid groups present in the material. The surface groups with $\mathrm{pK}_{\mathrm{a}}$ values $\leq 10$ can only be titrated in aqueous solution (very strong acids). The acid number (AN) at equivalence point 1 (EQP1) occurs near the measured potential of -100 $\mathrm{mV}$ and equivalence point 2 (EQP2) is found near the potential of $+40 \mathrm{mV}$; the volume of acid titrant at that $\mathrm{EQP}$ value is then referenced to a blank value (deionised water) and converted to an $\mathrm{AN}$, using this equation:

$$
A N\left(m g K O H g^{-1}\right)=\left(\left[\text { Blank value }\left(\mathrm{cm}^{3}\right)\right]-\left[E Q P\left(\mathrm{~cm}^{3}\right)\right]\right) * 56.11 / m
$$

where, $56.11 \mathrm{~g} \mathrm{~mol}^{-1}$ is the molar mass of potassium hydroxide $(\mathrm{KOH})$ and $m$ is the mass of the sample (g).

Scanning electron microscopy (SEM) images were obtained with a JEOL JSM-7500F with an accelerating voltage of $5.0 \mathrm{kV}$ and an emission current of $10 \mathrm{~mA}$. Scanning transmission electron microscopy (STEM, Hitachi HD2300A) instrument was also used.

The $\mu$-SCs were tested by cyclic voltammetry (CV) using a CHI720 electrochemical workstation. Galvanostatic charge-discharge (GCD) was carried out on a Neware Galvanostat (100 mA, 5 V) with Test Control V.5.0 software. Electrochemical impedance spectroscopy (EIS) was carried out with Solartron SI1260 and a potentiostat/galvanostat (EG\&G Model 283, Princeton Applied Research) at the open circuit potential with an AC amplitude of $10 \mathrm{mV}$ in the frequency range of $0.01 \mathrm{~Hz}-1 \mathrm{MHz}$. Life-cycle testing of the FLG(NH $\mathrm{NH}_{3}$-MWCNT(Acid) device was carried out with Gamry Reference 600 potentiostat at 0.5 $\mathrm{mA} \mathrm{cm}{ }^{-2}$. Device capacitance values were calculated using equations given in the Supporting Information. In-situ Raman microscopy was carried out on a Renishaw InVia Reflex Raman Microscope with a 785 $\mathrm{nm}$ laser. The $\mu$-SC[FLG(NH3)-MWCNT(Acid)] device was connected to an IviumStat potentiostat and cycled at $5 \mathrm{mV} \mathrm{s}^{-1}$ between $0-0.85 \mathrm{~V}$.

\section{Results and discussion}

\section{Characterisation of plasma-treated materials}

Plasma is used to treat the surface of nanostructured carbons to impart functional groups and alter the surface chemistry and is a complex process, as shown in Fig. 1a. Surface treatment of carbons, such as FLG and MWCNT, has the dual purpose of easing processability by improving dispersion and providing surface groups for possible pseudo-capacitance enhancements in electrochemical energy storage applications. The FLG and MWCNT materials have already existing surface chemistry prior to treatment, from adsorbed molecules and surface functionalities. The adsorbed molecules could include moisture and atmospheric gases. Haydale Ltd.'s patented plasma functionalization technique was used on FLG and MWCNT to increase the materials' pseudo-capacitance and also increase the interaction of FLGs with MWCNTs. 
Table 1 Materials and their treatment parameters.

\begin{aligned} & \hline FLG MWCNT \\ & \hline FLG MWCNT \\ & FLG MWCNT(Acid) \\ & FLG(Ar) MWCNT \\ & FLG(Ar) MWCNT(Acid) \\ & FLG( $\left.\mathrm{H}_{2} / \mathrm{Ar}\right)$ MWCNT \\ & $\mathrm{FLG}\left(\mathrm{H}_{2} / \mathrm{Ar}\right)$ MWCNT(Acid) \\ & $\mathrm{FLG}\left(\mathrm{NH}_{3}\right)$ MWCNT \\ & $\mathrm{FLG}\left(\mathrm{NH}_{3}\right)$ MWCNT(Acid) \\ & \hline\end{aligned}

A range of plasma treatments was trialled. FLG was either treated with argon plasma, hydrogen and argon mixed plasma or ammonia plasma, and MWCNT was treated with acid plasma (Table 1). Hydrogen and argon mixed plasma treatment was conducted using 3\% hydrogen in argon gas. The starting FLG material has a platelet morphology of many different particle sizes, from as small as $100 \mathrm{~nm}$ up to larger aggregates, as seen by SEM imaging (Fig. 1a). STEM imaging shows the number of graphene layers can vary from 2 to 12 (Supporting Information Fig. S1). The starting MWCNT material has spaghetti-like morphology and, after plasma processing, becomes much less aggregated and individual tubes can be seen more clearly (Fig. 1b). Previous reports have suggested which types of functional groups could be present after these plasma treatments, but each experimental system is different in terms of gas flow, pressure, temperature, impurities and starting material. ${ }^{24}$ The FLG material has a high quantity of carbon present with minimal quantities of hydrogen, nitrogen and an oxygen content of $\sim 6 \%$ by elemental microanalysis (Table 2).

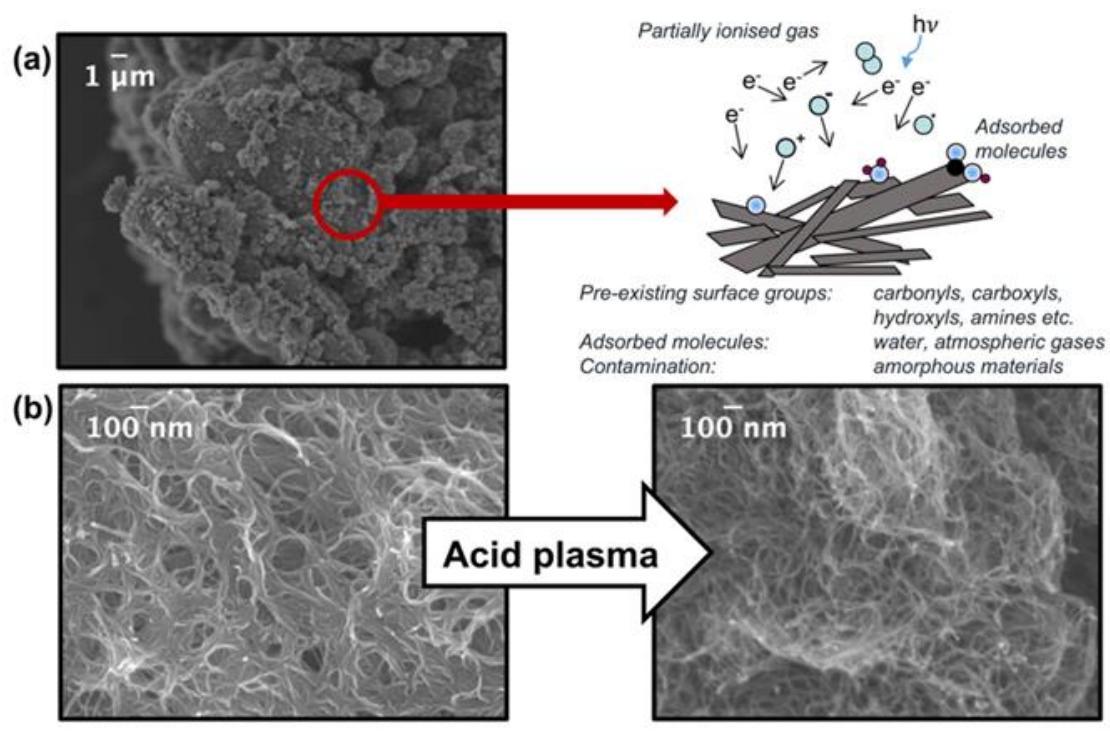

Fig. 1 (a) SEM image of FLG and a schematic diagram for the plasma functionalization of FLG flakes and (b) SEM image of MWCNT before and after plasma processing.

XPS studies of the FLG and MWCNT materials before plasma treatment detect the expected C 1s peak. A small but significant $\mathrm{O}$ 1s peak and a negligible $\mathrm{N}$ 1s peak are also observed as minor impurities, which are likely to have been introduced during the manufacturing processes and is standard for these materials. One example of the original spectra are shown in Supporting Information Fig. S2. A statistical analysis of repeated spectra per sample was carried out to investigate the consistency of testing and material processing. Nine spectra were generated for all the materials except FLG( $\left.\mathrm{NH}_{3}\right)$, MWCNT and MWNCT(Acid), each with three replicates. The average atomic \% (at.\%) and error (plus and minus one standard deviation) are shown in Fig. 2. The $\mathrm{C}$ 1s and $\mathrm{O}$ 1s peaks were fitted with consistent components that correspond to the functionalities found on the surface of these types of 
materials, identified by Fourier-Transform Infrared Spectroscopy (FTIR) and other methods. The components were identified using relevant literature based upon similar materials and interpretation of the data. ${ }^{10,25}$ The peak components' average percentage composition and error, described by plus and minus one standard deviation of the mean, are shown in Fig. 2. Two error bars are presented illustrating the position of the peak component and the percentage composition. The $\mathrm{C} 1 \mathrm{~s}$ peak was divided into 5 components and the $\mathrm{O} 1 \mathrm{~s}$ peak into 3 components and these are shown in Supporting Information Table $\mathrm{S} 1$. The $\mathrm{N} 1 \mathrm{~s}$ content is below $1 \%$ for all materials and the spectra are noisy, which makes it difficult to resolve into consistent and reliable components, therefore, the total average $\mathrm{N}$ at.\% is shown. The carbon-nitrogen bonds in the $\mathrm{C}$ 1s peak are described in Table S1, but the overall low content of nitrogen in these compounds means they would have very low proportions compared with the carbonoxygen bonds at the equivalent binding energies. The hydroxyl peak components in the $\mathrm{C} 1 \mathrm{~s}$ and $\mathrm{O} 1 \mathrm{~s}$ peaks at binding energies of 286.3 and $532.2 \mathrm{eV}$, respectively, also describe ether and epoxy functionalities; these are likely to be less common than hydroxyl groups, and therefore the hydroxyl functionalities alone will be detailed further in these analyses.

Table 2 Elemental microanalysis of parent FLG. Two replicates were averaged from five different batches of material.

\begin{tabular}{cccccc}
\hline Material & \multicolumn{5}{c}{ Dry basis \% } \\
\hline FLG & $92.5 \pm 0.3$ & $0.3 \pm 0.0$ & $0.8 \pm 0.1$ & $0.0 \pm 0.0$ & $6.1 \pm 0.2$ \\
\hline
\end{tabular}

't-tests' were used to find significant differences between the peaks' composition at a 0.05 confidence level. The FLG and MWCNT spectra show quite different composition levels, which could be due to their flake and tubular-like structures, respectively. MWCNT has a much higher carbon content (99.0 at.\%) than FLG and MWCNT also contains a high $\mathrm{sp}^{2}$ carbon content because it has fewer defects. The $\mathrm{C} \mathrm{sp}{ }^{2}$ content is lower than predicted, which could be because this material contains contaminants such as amorphous carbon. The shape of the $\mathrm{O} 1 \mathrm{~s}$ peak is dissimilar in the two materials due to their structures. MWCNT will have a higher concentration of functionalization at the ends of the nanotubes and at defect sites. FLG is more likely to be functionalized at the edges of the flakes and doped in the basal plane. After acid functionalization, a larger number of $\mathrm{C}-\mathrm{O}$ bonds are evident in the MWCNT(Acid) spectra, which could be due to functionalities such as hydroxyl (aliphatic/aromatic) groups. As the $\mathrm{C}-\mathrm{O}$ functionality increases (in both $\mathrm{C} 1 \mathrm{~s}$ and $\mathrm{O} 1 \mathrm{~s}$ spectra), there is a concurrent decrease in $\mathrm{C} \mathrm{sp}^{2}$ concentration, as expected.
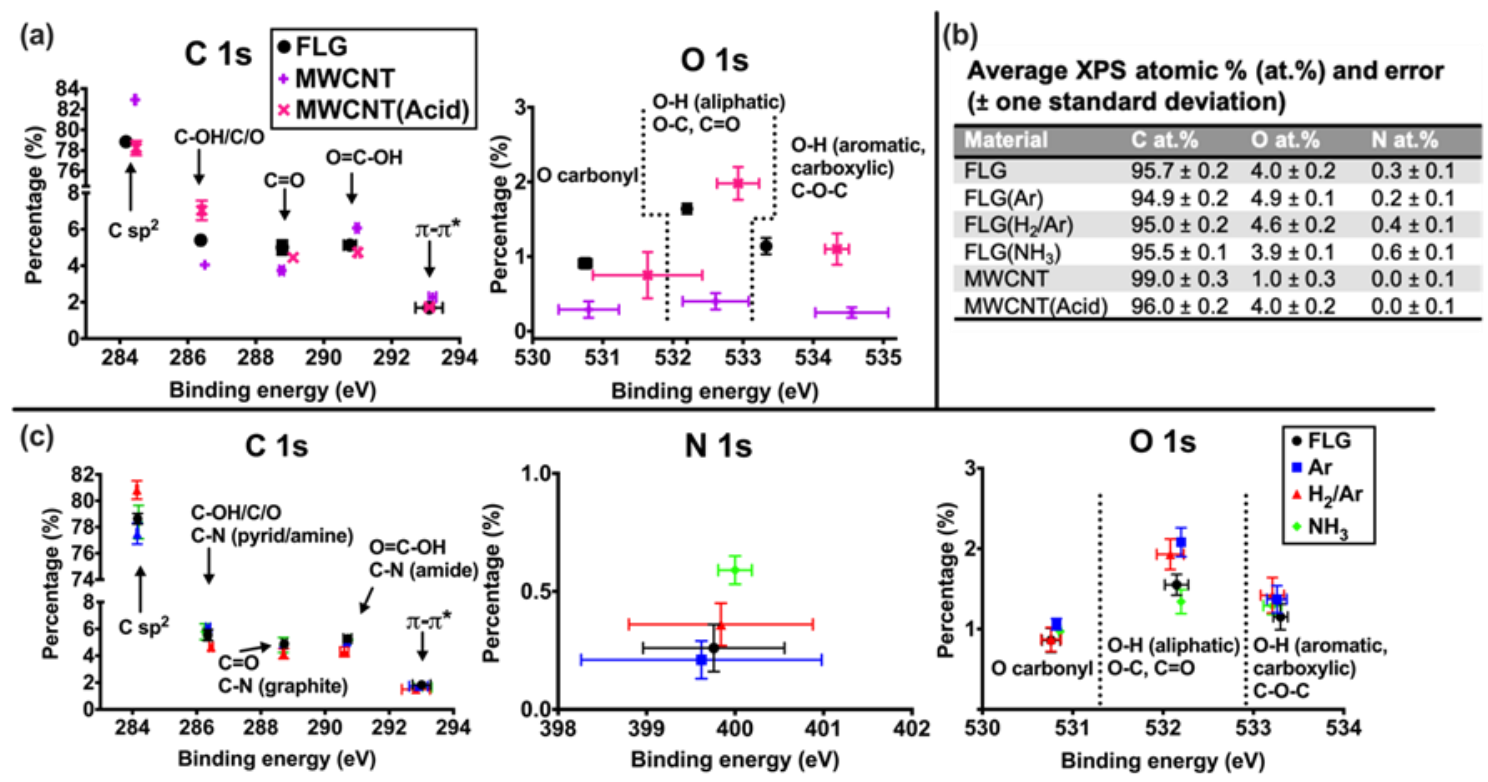

Fig. 2 XPS statistical analysis of functionalization by plasma. (a) Graphical representation of $\mathrm{C} 1 \mathrm{~s}$ and $\mathrm{O}$ 1 s functional groups of FLG, MWCNT and MWCNT(Acid) materials. (b) Table detailing atomic \% of all materials. (c) Graphical representation of $\mathrm{C} 1 \mathrm{~s}, \mathrm{~N}$ 1s and $\mathrm{O} 1 \mathrm{~s}$ functional groups of FLG and the 
functionalised FLG materials. (Error bars are occasionally masked by symbols and represent the standard deviation from the average peak component binding energy and composition percentage. Nine replicate spectra were obtained, except for $\mathrm{NH}_{3}$, MWCNT and MWCNT(Acid), which had three replicate spectra.)

FLG(Ar) has shown small significant differences from the FLG starting material in both $\mathrm{C}$ 1s and $\mathrm{O} 1 \mathrm{~s}$ spectra, but there is an overall significant increase in oxygen content from 4.0 to 4.9 at.\%. The peak component changes comprise of a decrease in $\mathrm{C} \mathrm{sp}^{2}$ and an increase in hydroxyl groups from the $\mathrm{O} 1 \mathrm{~s}$ peak. The increase in hydroxyl groups is also seen in the $\mathrm{C} 1 \mathrm{~s}$ peak component, but after statistical analysis is carried out, the change is insignificant at the 0.05 level. The $\mathrm{C} 1 \mathrm{~s}$ peak of the $\mathrm{FLG}\left(\mathrm{H}_{2} / \mathrm{Ar}\right)$ material was significantly different to the starting FLG material with higher $\mathrm{C} \mathrm{sp}{ }^{2}$ content due to the reducing nature of the $\mathrm{H}_{2}$ environment and a correspondingly lower $\mathrm{C} 2, \mathrm{C} 3$ and $\mathrm{C} 4$ content. When compared with the $\mathrm{O}$ 1 s peak, the $\mathrm{O} 2$ and $\mathrm{O} 3$ components have slightly increased, which suggests an opposite effect. However, this result could be explained by lower $\mathrm{O} 1 \mathrm{~s}$ photoelectron kinetic energies than those of the $\mathrm{C} 1 \mathrm{~s}$, which means the $\mathrm{O} 1 \mathrm{~s}$ is slightly more surface specific because the sampling depth is smaller. ${ }^{26}$ Plasma treatment of FLG with ammonia resulted in a significantly higher $\mathrm{N} 1 \mathrm{~s}$ content and slightly lower $\mathrm{O} 1 \mathrm{~s}$ content (due to aliphatic hydroxyl groups) compared with the material prior to treatment, even though the ammonia treatment was at a low level of functionalization. The minor changes in $\mathrm{C} 1 \mathrm{~s}$ spectra and total at.\% of $\mathrm{FLG}\left(\mathrm{NH}_{3}\right)$ following plasma treatment in ammonia also supports the hypothesis that the FLG was functionalized to a low level with nitrogen groups.

Following plasma treatment and surface functionalization, a change in the zeta $(\zeta)$ potential of these materials is expected. $\zeta$ potential values of FLG in aqueous dispersions both before and after plasma treatment are shown in Fig. 3. These $\mathrm{pH}$-sensitive measurements provide a suggestion as to the overall surface charge of the material because the material dispersibility in different $\mathrm{pH}$ environments can be dependent upon the acidity of the material's functionalities. Typically, a particle is thought to be able to form a stable dispersion if the $\zeta$ potential is measured above $+30 \mathrm{mV}$ and below $-30 \mathrm{mV} .{ }^{27} \mathrm{In}$ general, ionisable groups, such as carboxylic acids and hydroxyls, aid dispersion in neutral and alkaline environments due to hydroxyl de-protonation in water. The measured potential should therefore be directly proportionate to the concentration of ionized groups at different $\mathrm{pH}$ values. ${ }^{28}$ This suggests FLG, FLG(Ar) and FLG( $\left.\mathrm{NH}_{3}\right)$ have a greater number of ionized groups compared to $\mathrm{FLG}\left(\mathrm{H}_{2} / \mathrm{Ar}\right)$ at neutral $\mathrm{pH}$ (to a 0.05 significance level). These ionisable groups could be carboxyl groups and/or hydroxyl groups (aromatic or aliphatic). In acidic environments, the amine groups in the $\mathrm{FLG}\left(\mathrm{NH}_{3}\right)$ material are protonated and provide an overall positive surface charge. FLG(Ar) could potentially have a larger number of hydroxyl groups that could be positioned close to the carboxyl groups and are capable of stabilising the charge in an acidic environment. These occurrences are described by Konkena et al. as being more acidic than stand-alone carboxyl groups. ${ }^{10}$ In basic environments, the materials are of similar stability due to the compression of the double layer at high ionic strengths. ${ }^{29}$
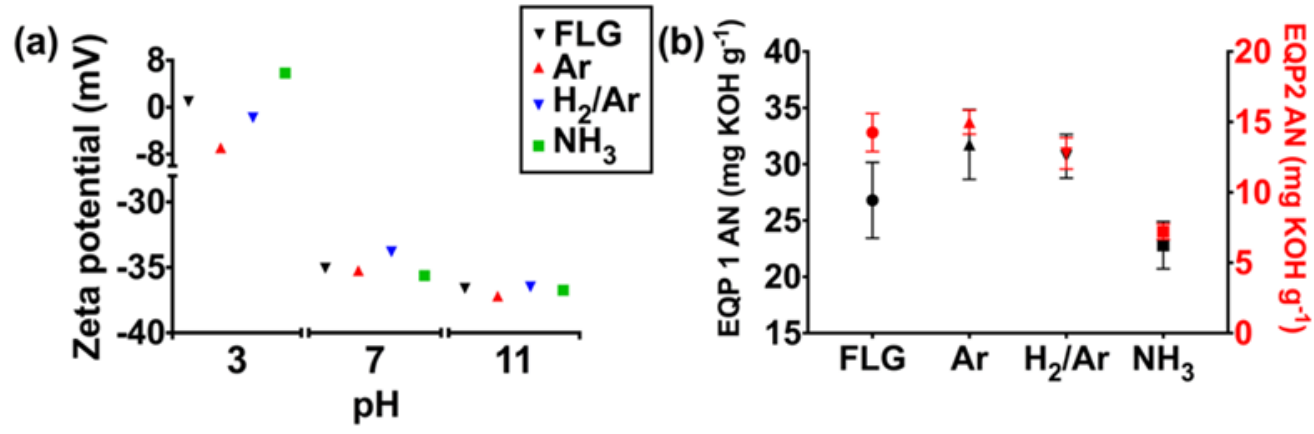

Fig. 3 Characterization of FLG by (a) zeta potential and (b) acid-base titration. Zeta potential sample size for each material: $\mathrm{pH} 3-7$ replicates, $\mathrm{pH} 7-21$ replicates, $\mathrm{pH} 11-7$ replicates. Acid-base titration sample size: 4 replicates. $(\mathrm{AN}=$ Acid number, $\mathrm{EQP}=$ equivalence point)

An acid-base titration was used to determine the surface charge density of the materials and the corresponding titration curves are shown in Supporting Information Fig. S3. The curves were resolved to find the equivalence points (EQPs), which occur when sufficient titrant is added to completely neutralise 
the solution. In this study, there are two EQPs showing two strongly acidic groups, which could be assigned to carboxyl groups and hydroxyl groups. The volume of hydrochloric acid added at the EQP is used to find an acid number (AN) using equation (1). FLG( $\mathrm{H}_{2} / \mathrm{Ar}$ ) and FLG(Ar) do not shift EQP1 or EQP2 to a higher acid number compared to the FLG starting material (at a 0.05 significant level). FLG(H $\left.\mathrm{H}_{2} / \mathrm{Ar}\right)$ does shift EQP2 to a lower acid number than FLG(Ar), which is significant to a 0.05 level and could be explained by the introduction of more hydroxyl groups onto the surface of FLG(Ar). FLG $\left(\mathrm{NH}_{3}\right)$ shifted both EQP1 and EQP2 to lower acid numbers to a 0.05 significant level due to the introduction of basic amine groups. MWCNT has a much lower average acid number in Table S2, indicating lower functionality, whereas after acid plasma functionalization the average acid number was increased, results which are supported by the XPS analysis.

Table 3 Material compositions in ink manufacture with PEDOT/PSS binder and resulting coating measurements of thickness and mass loading, with a PEDOT/PSS-FLG-MWCNT mass ratio of 1:3:1, respectively.

\begin{tabular}{llllll}
\hline FLG & MWCNT & $\begin{array}{l}\text { THICKNESS OF } \\
\text { FILM }(\mu \mathrm{m})\end{array}$ & $\begin{array}{l}\text { VOLUME PER } \\
\text { DEVICE }\left(\mathrm{cm}^{3}\right)\end{array}$ & $\begin{array}{l}\text { MASS LOADING } \\
\text { PER DEVICE }(\mathrm{g})\end{array}$ & $\begin{array}{l}\text { DENSITY } \\
\left(\mathrm{g} \mathrm{cm}^{-3}\right)\end{array}$ \\
\hline FLG & MWCNT & 8.4 & 0.00084 & 0.00069 & 0.82 \\
FLG & MWCNT(Acid) & 18.6 & 0.00186 & 0.00114 & 0.61 \\
FLG(Ar) & MWCNT & 13.5 & 0.00135 & 0.00110 & 0.81 \\
FLG(Ar) & MWCNT(Acid) & 7.1 & 0.00071 & 0.00062 & 0.87 \\
FLG( $\left.\mathrm{H}_{2} / \mathrm{Ar}\right)$ & MWCNT & 13.8 & 0.00138 & 0.00107 & 0.78 \\
FLG $\left(\mathrm{H}_{2} / \mathrm{Ar}\right)$ & MWCNT(Acid) & 13.1 & 0.00131 & 0.00080 & 0.61 \\
FLG $\left(\mathrm{NH}_{3}\right)$ & MWCNT & 9.9 & 0.00099 & 0.00087 & 0.88 \\
FLG $\left(\mathrm{NH}_{3}\right)$ & MWCNT(Acid) & 6.2 & 0.00062 & 0.00041 & 0.66 \\
\hline
\end{tabular}

Following surface functionalization of the plasma-treated carbons, these materials were formulated into conductive dispersions with PEDOT/PSS to aid the manufacture of flexible electrode films. After a vigorous investigation, a mass ratio of 1:3:1 PEDOT/PSS-FLG-MWCNT (at a solid content of $1.5 \mathrm{wt} . \%$ in the dispersion) was found to produce a high-quality film with maximum content of FLG, which should correspond with the largest device capacitance by volume. Table 3 shows the carbon compositions that were prepared with PEDOT/PSS into inks, which allows for comparison of unfunctionalized carbon materials, with variants where either one or both carbon types were functionalised. The various conductive inks were cast as flexible electrode films onto gold-coated polyethylene terephthalate (PET) 
substrates.

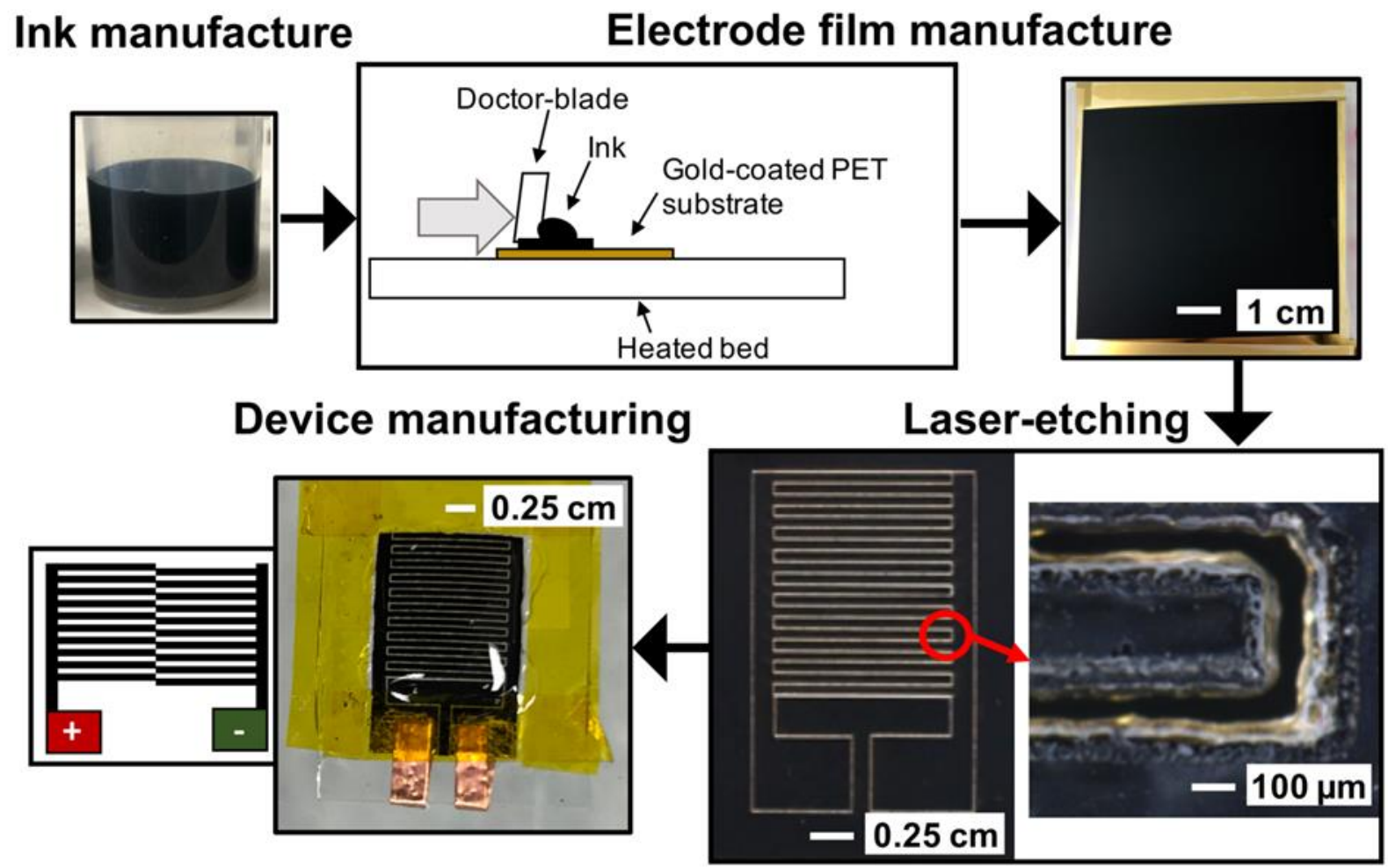

Fig. 4 shows the fabrication process of these films into flexible $\mu$-SC devices with interdigitated electrodes. Each film was manufactured using a fresh ink to ensure consistent solid contents across all the materials.

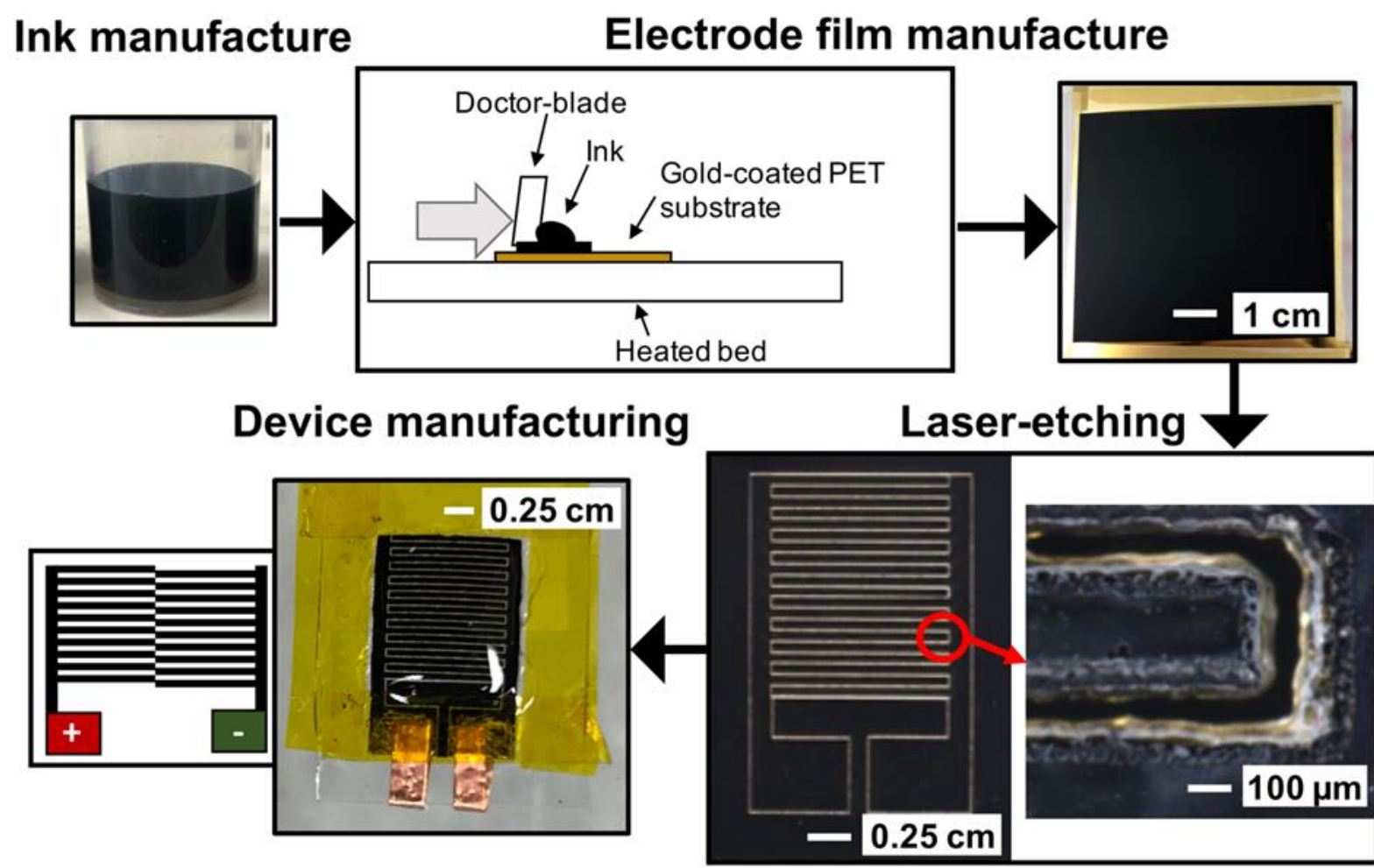

Fig. 4 Manufacture of electrode films and $\mu$-SC devices. A PEDOT/PSS-FLG-MWCNT aqueous-based ink was initially synthesised by tip sonication and applied onto a gold-coated PET substrate by doctorblade. The dried coating was etched into an interdigitated electrode pattern with a $\mathrm{CO}_{2}$ laser. The tabs at 
the bottom of the etching pattern were mechanically scratched to remove the PEDOT/PSS-FLG-MWCNT coating only and copper tape contacts were stuck onto the gold coating. Finally, the gel electrolyte was applied to the surface of the etched pattern and left to dry.

\section{Studies of graphene microsupercapacitors}

The total area of the active materials in the device was $0.83 \mathrm{~cm}^{2}$. For each PEDOT/PSS-FLG-MWCNT combination, the same volume of dispersion was applied to the doctor-blade for coating, however the resulting thickness and mass loading of these differed, which implies the composite materials have interacted differently due to their surface functionalities. The functionalized surface of MWCNT(Acid) enables the nanotubes to disperse to a higher degree in aqueous solutions than MWCNT and therefore, the composite films of FLG-MWCNT(Acid) and FLG(NH3)-MWCNT(Acid) have similarly low densities, 0.61 and $0.66 \mathrm{~g} \mathrm{~cm}^{-3}$ respectively. FLG-MWCNT and FLG(NH $\mathrm{NH}_{3}$-MWCNT have comparable densities of 0.82 and $0.88 \mathrm{~g} \mathrm{~cm}^{-3}$, respectively, and both have untreated MWCNT (Table 3).
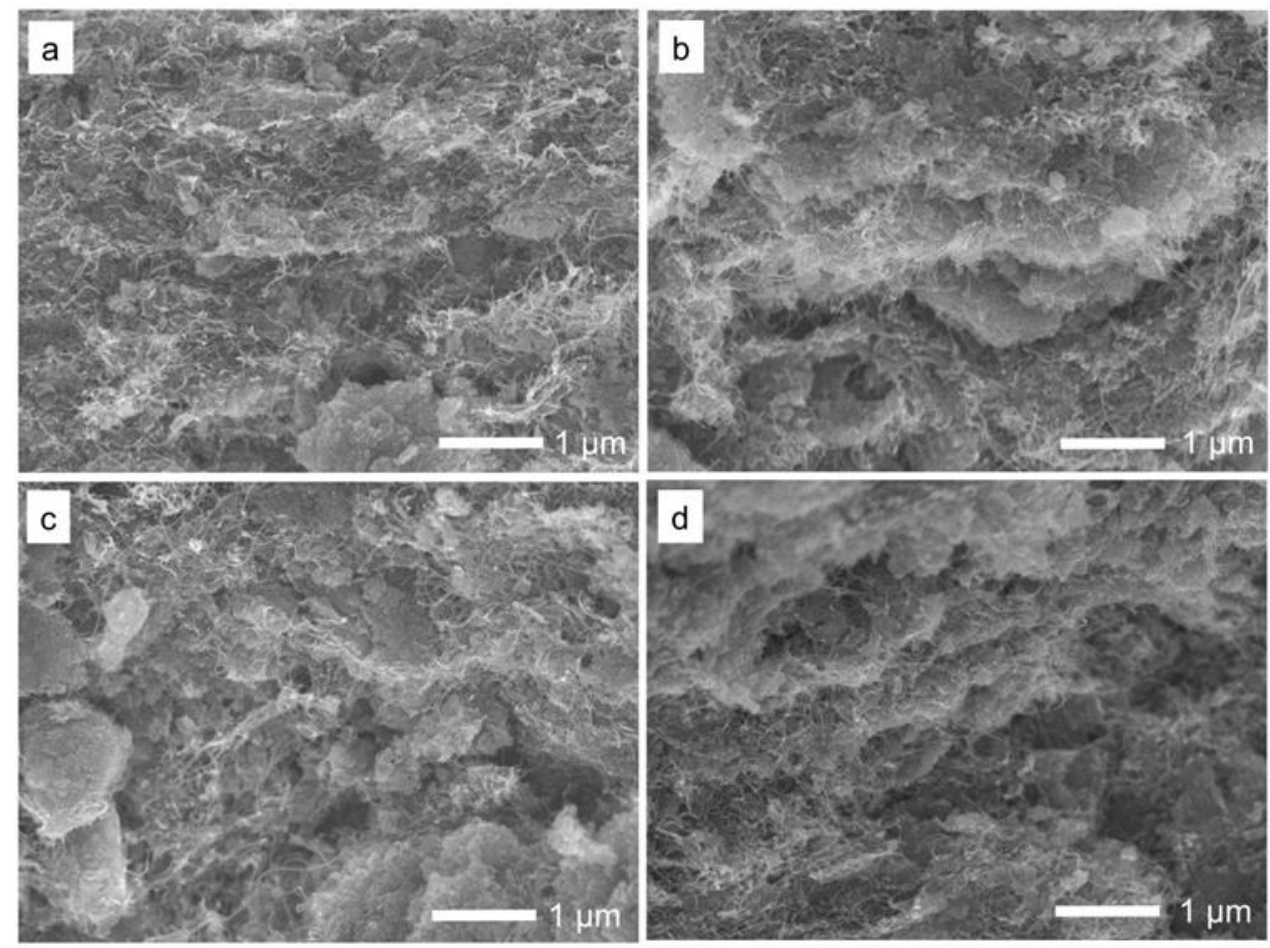

Fig. 5 SEM images of cross-sections of films supported on carbon tape: (a) FLG-MWCNT, (b) FLGMWCNT(Acid), (c) FLG(NH $\left.\mathrm{NH}_{3}\right)-\mathrm{MWCNT}$ and (d) FLG(NH $\left.\mathrm{NH}_{3}\right)-\mathrm{MWCNT}$ (Acid).

The cross-sectional SEM images of the as-prepared films were investigated (Fig. 5). It is clear that the MWCNTs distributed well around the FLG and PEDOT/PSS particles in all films. Specifically, the MWCNT(Acid) are better dispersed in their composite films (Fig. 5b and 5d) compared to MWCNT (no plasma treatment, in Fig. 5a and 5c). The two composite films made with MWCNT(Acid) also appear to be more layered in their structure than the MWCNT variants. This layered structure could be due to the acid treated MWCNTs having better dispersion and a stronger interaction with the FLG materials, thereby forming more defined networks of materials. In addition, there seems to be a higher number of areas without any nanotubes in the FLG-MWCNT and FLG( $\left.\mathrm{NH}_{3}\right)-\mathrm{MWCNT}$ cross-sections, which further suggests there is a less homogeneous distribution of MWCNT throughout those films. 

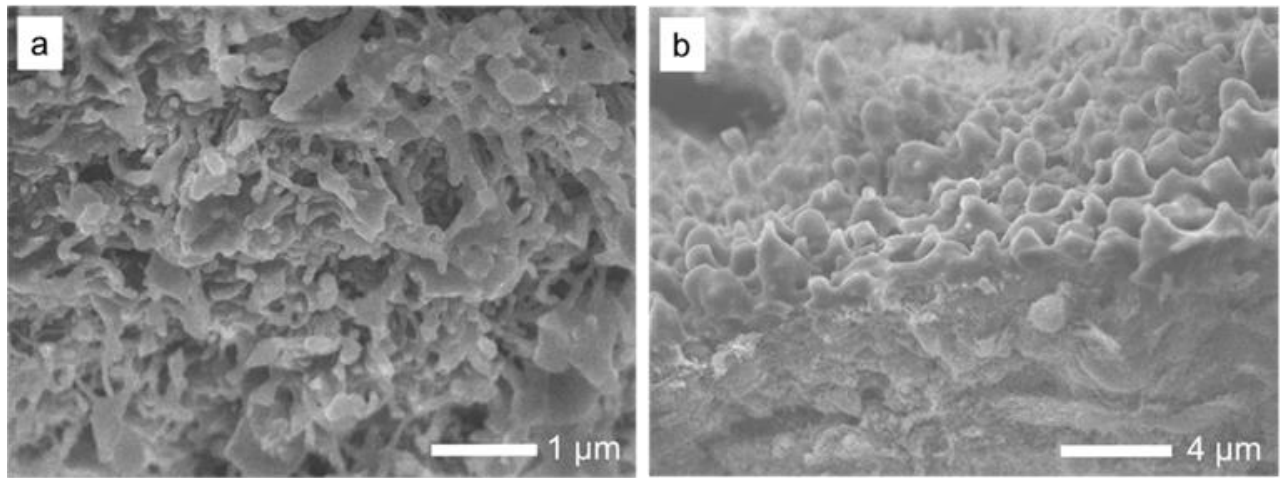

Fig. 6 SEM images of cross-section of laser-etched films supported on PET substrate and carbon tape: (a) FLG-MWCNT and (b) FLG(NH $\mathrm{NH}_{3}$-MWCNT.

To fabricate $\mu$-SCs from the films, interdigitated patterns were etched with a $\mathrm{CO}_{2}$ laser cutter system to create channels between positive and negative electrodes. The composite films were laser-etched into a pattern of two electrodes with a total of 20 fingers $(400 \mu \mathrm{m} \times 8000 \mu \mathrm{m})$, an interspace between fingers $(100 \mu \mathrm{m})$ and an outer edge $(1000 \mu \mathrm{m})$, as reported previously. ${ }^{3}$ Previous studies suggest that an increased capacitance and rate capability are achieved with a low interspace separation because it allows the active material loading to be maximised while minimising the ion diffusion pathway between the two oppositely charged electrodes (i.e. anode and cathode) ${ }^{30}$ In previous work, it has been shown that the lowest interspace of $100 \mu \mathrm{m}$ can be achieved without shorting the electrical circuit.3 The laser-etching effect on the electrode fingers is shown in Fig. 6. There are slight differences between FLG-MWCNT and FLG $\left(\mathrm{NH}_{3}\right)$-MWCNT because smaller tubular structures can be seen in FLG-MWCNT (Fig. 6a) and more globular structures can be seen in FLG(NH3)-MWCNT (Fig. 6b). These surface structures are only a few microns in depth and should not impact the performance of the respective devices as the surfaces still appear to be porous and also allow electrolyte to diffuse further into the electrode fingers. ${ }^{3}$
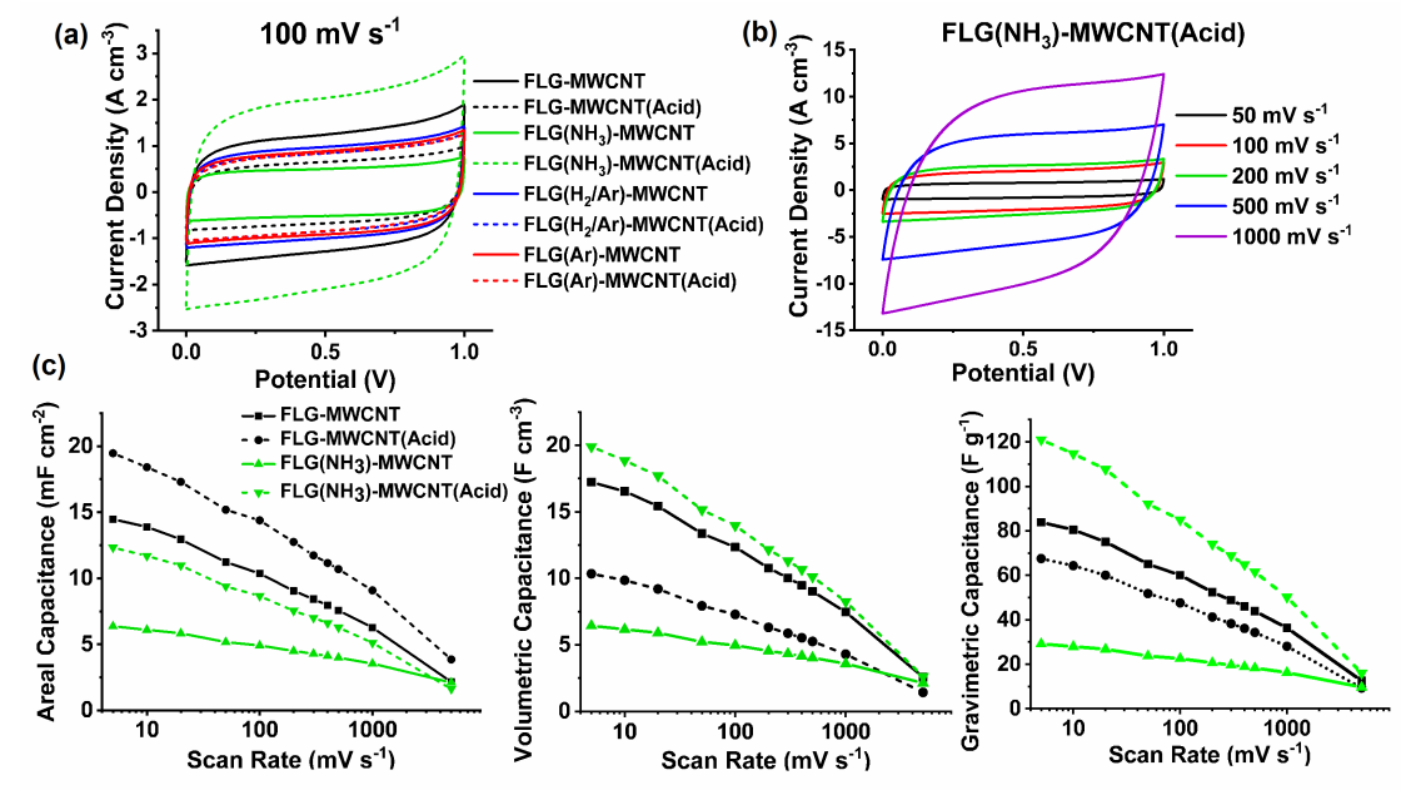

Fig. 7 (a) CV curves at $100 \mathrm{mV} \mathrm{s}^{-1}$ for all two-electrode devices. (b) CV curves for $\mu$-SC[FLG( $\mathrm{NH}_{3}$ )MWNCT(Acid)] between 50 and $1000 \mathrm{mV} \mathrm{s}^{-1}$. (c) Areal, volumetric and gravimetric capacitances with selected materials.

Following a solid-state PVA- $\mathrm{H}_{3} \mathrm{PO}_{4}$ electrolyte overcoat, flexible $\mu$-SC devices were tested. The performance of the resulting devices was initially evaluated using $\mathrm{CV}$, which was carried out as a function of scan rate $\left(5-5000 \mathrm{mV} \mathrm{s}^{-1}\right)$ with a voltage window from 0 to $1 \mathrm{~V}$. An important consideration for $\mu$ $\mathrm{SCs}$ is the device area since the mass of the electrode materials is very small, making gravimetric specific 
capacitance an inappropriate performance metric. When comparing the performance of different materials, volumetric energy and power densities are more appropriate than areal values to understand the intrinsic properties of the electrode material. ${ }^{21}$ Increasing the thickness of the film can increase the areal energy density if the electrode materials are highly conductive. All devices show near ideal capacitive behaviour with rectangular CV curves (Fig. 7a). $\mu$-SC[FLG( $\mathrm{NH}_{3}$ )-MWCNT(Acid)] is shown to be operating at a higher current density and displays ideal behaviour between scan rates of 50 and 1000 $\mathrm{mV} \mathrm{s}^{-1}$ (Fig. 7b), which indicates that fast ion transport is maintained even at high rates. $\mu$-SC[FLGMWCNT(Acid)] has increased the areal capacitance at all scan rates compared with the untreated composite material device (Fig. 7c). In addition, the ammonia plasma treated FLG reduced the performance of $\mu$-SC[FLG( $\left.\left.\mathrm{NH}_{3}\right)-\mathrm{MWCNT}\right]$ in areal, volumetric and gravimetric capacitances. However, the combination of the ammonia treated FLG and acid treated MWCNT has slightly improved the areal capacitance and vastly improved the volumetric and gravimetric capacitances of $\mu$-SC[FLG( $\left(\mathrm{NH}_{3}\right)$ MWCNT(Acid)].

In terms of volumetric or gravimetric capacitance, the $\mu$-SC[FLG(NH$)-M W C N T(A c i d)]$ outperforms $\mu$ SC[FLG-MWCNT(Acid)], which relates to the change in density and thickness of the films with changed material composition (Table 3). $\mu$-SC[FLG(NH3)-MWCNT(Acid)] yields the highest specific device capacitance when normalised by volume $\left(19.9 \mathrm{~F} \mathrm{~cm}^{-3}\right.$ at $5 \mathrm{mV} \mathrm{s}^{-1}$ and $12.2 \mathrm{~F} \mathrm{~cm}^{-3}$ at $\left.200 \mathrm{mV} \mathrm{s}^{-1}\right)$, whereas $\mu$-SC[FLG-MWCNT(Acid)] generates the highest specific device capacitance when normalised by device area $\left(19.5 \mathrm{mF} \mathrm{cm}^{-2}\right.$ at $5 \mathrm{mV} \mathrm{s}^{-1}$ and $12.8 \mathrm{mF} \mathrm{cm}^{-2}$ at $200 \mathrm{mV} \mathrm{s}^{-1}$ ) (Fig. 7c). The mass of active material and film thickness for $\mu$-SC[FLG-MWCNT(Acid)] are approximately three times that of the $\mu$ $\mathrm{SC}\left[\mathrm{FLG}\left(\mathrm{NH}_{3}\right)\right.$-MWCNT(Acid)] which explains the increase in areal capacitance of the former compared to the latter. The areal capacitance is a less accurate representation of the performance of these materials. When mass and volume are considered the $\mu$-SC[FLG(NH3)-MWCNT(Acid)] device shows superior performance. The gravimetric capacitance values are reported in terms of electrode mass in Fig. 7c and these values for $\mu$-SC[FLG( $\left.\mathrm{NH}_{3}\right)$-MWCNT(Acid)] confirm high performance. However, it is more suitable to report the device performances in these architectures and these are shown in the Supporting Information. $\mu$-SCs containing MWCNT(Acid) have a poorer rate capability than the other devices, which is unexpected when considering the earlier reported lower densities but could be due to the less conductive nature of the acid functionalities of the MWCNT material in the electrodes. The following four devices will be further evaluated by GCD and EIS analysis because the CV results indicate some interesting contrasts between the untreated and $\mathrm{NH}_{3}$ plasma surface treatments of FLG: FLG-MWCNT, FLGMWCNT(Acid), FLG(NH $\mathrm{NH}_{3}$-MWCNT and FLG( $\left.\mathrm{NH}_{3}\right)$-MWCNT(Acid).
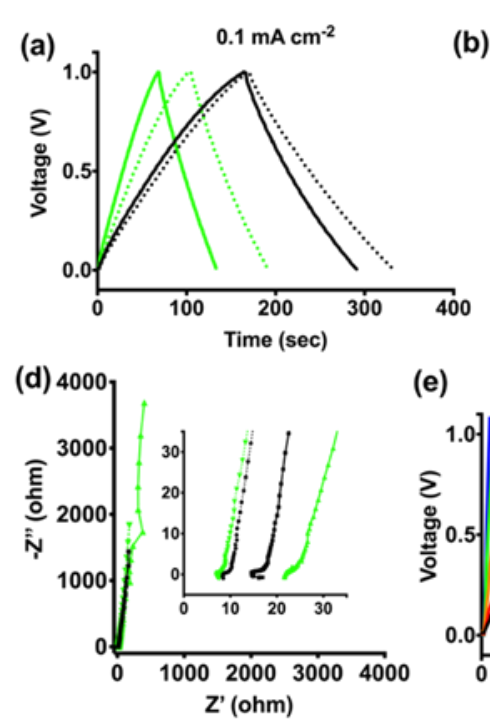

(b) $\stackrel{\text { ? }}{\mathrm{E}}$

(e)
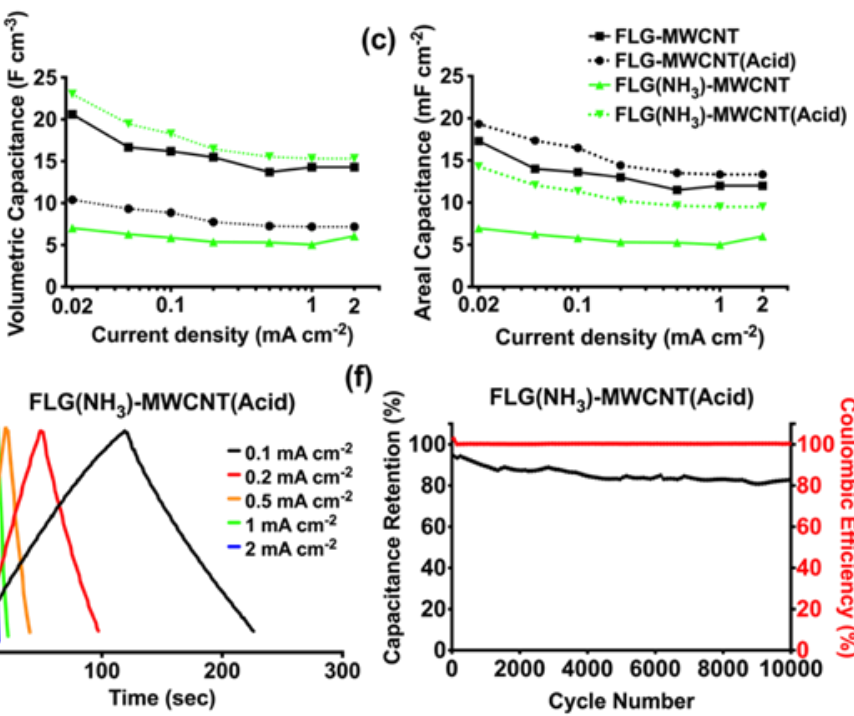

Fig. 8 (a) Charge-discharge curves with select materials at current density of $0.1 \mathrm{~mA} \mathrm{~cm}{ }^{-2}$. (b) Volumetric and (c) areal capacitance values from GCD analysis. (d) Nyquist plots for materials with a magnification of the high frequency region provided in the inset. (e) Charge-discharge curves of $\mu$-SC[FLG $\left(\mathrm{NH}_{3}\right)$ - 
MWCNT(Acid)] at multiple scan rates. (f) Life cycle analysis over 10000 cycles for $\mu$-SC[FLG(NH $\mathrm{NH}_{3}$ MWCNT(Acid)], charged and discharged at $0.5 \mathrm{~mA} \mathrm{~cm} \mathrm{~cm}^{-2}$.

The same trends found in CV studies above, are found when examining the GCD curves of the $\mu$-SCs at varying current densities $\left(0.02 \mathrm{~mA} \mathrm{~cm}{ }^{-2}\right.$ to $\left.2 \mathrm{~mA} \mathrm{~cm}^{-2}\right)$ (Fig. 8). All of the GCD curves at $0.1 \mathrm{~mA} \mathrm{~cm}{ }^{-2}$ show low cell resistance (a near-triangular shape), which confirms the presence of an efficient electric double layer in the electrode materials (Fig. 8a). $\mu$-SC[FLG( $\left(\mathrm{NH}_{3}\right)$-MWCNT(Acid)] has the highest volumetric capacitance of $16.5 \mathrm{~F} \mathrm{~cm}^{-3}$ at a current density of $0.2 \mathrm{~mA} \mathrm{~cm}^{-2}$ (Fig. $8 \mathrm{~b}$ ). $\mu$-SC[FLGMWCNT(Acid)] has the highest areal capacitance of $10.2 \mathrm{mF} \mathrm{cm}^{-2}$ at $0.2 \mathrm{~mA} \mathrm{~cm}^{-2}$ (Fig. 8c). In comparison to published material, these devices are competitive because they have simpler manufacturing routes yet comparable areal, volumetric and gravimetric capacitance values. Liu et al. developed an rGOPEDOT/PSS $\mu$-SC device, manufactured with the same laser-etching technique, which performed at 14.2 $\mathrm{F} \mathrm{cm}^{-3}$ at $200 \mathrm{mV} \mathrm{s}^{-1}$ (by CV); this device had a higher mass loading $(1.664 \mathrm{mg}$ ) and nearly double the thickness $(11.7 \mu \mathrm{m})$; the areal dimensions and number of electrodes in the device were consistent with this study. ${ }^{3}$ The production of GO flakes and rGO is lengthy and requires a number of environmentally unfriendly chemicals and so the benefits of using plasma to functionalize the FLG and MWCNT can be realised.

The Nyquist plots with these materials also show pure capacitive cell behaviour even at moderate frequencies $(15 \mathrm{~Hz})$, which could be due to the highly accessible surface of the PEDOT/PSS-FLGMWCNT materials (Fig. 8d). The real axis intercepts in the Nyquist plots provide the device equivalent series resistance, which appears lowest for $\mu$-SC[FLG(NH3)-MWCNT(Acid)], estimated to be $\sim 7 \mathrm{ohm}$. There is good similarity between the charge and discharge curves of the $\mu$-SC[FLG $\left(\mathrm{NH}_{3}\right)$ MWCNT(Acid)] device at different current densities (Fig. 8e), showing excellent capacitive characteristics, whereas a deviation from symmetric charge and discharge curves is noted with the unfunctionalized carbon equivalent (FLG-MWCNT) in Fig. 8 a at $0.1 \mathrm{~mA} \mathrm{~cm}{ }^{-2}$. The coulombic efficiency of $\mu$-SC[FLG(NH3)-MWCNT(Acid)] is very consistent and does not drop below $100 \%$ in 10,000 cycles (Fig. 8f). The discharge capacity retention of this device remains above $80 \%$ after 10000 cycles.

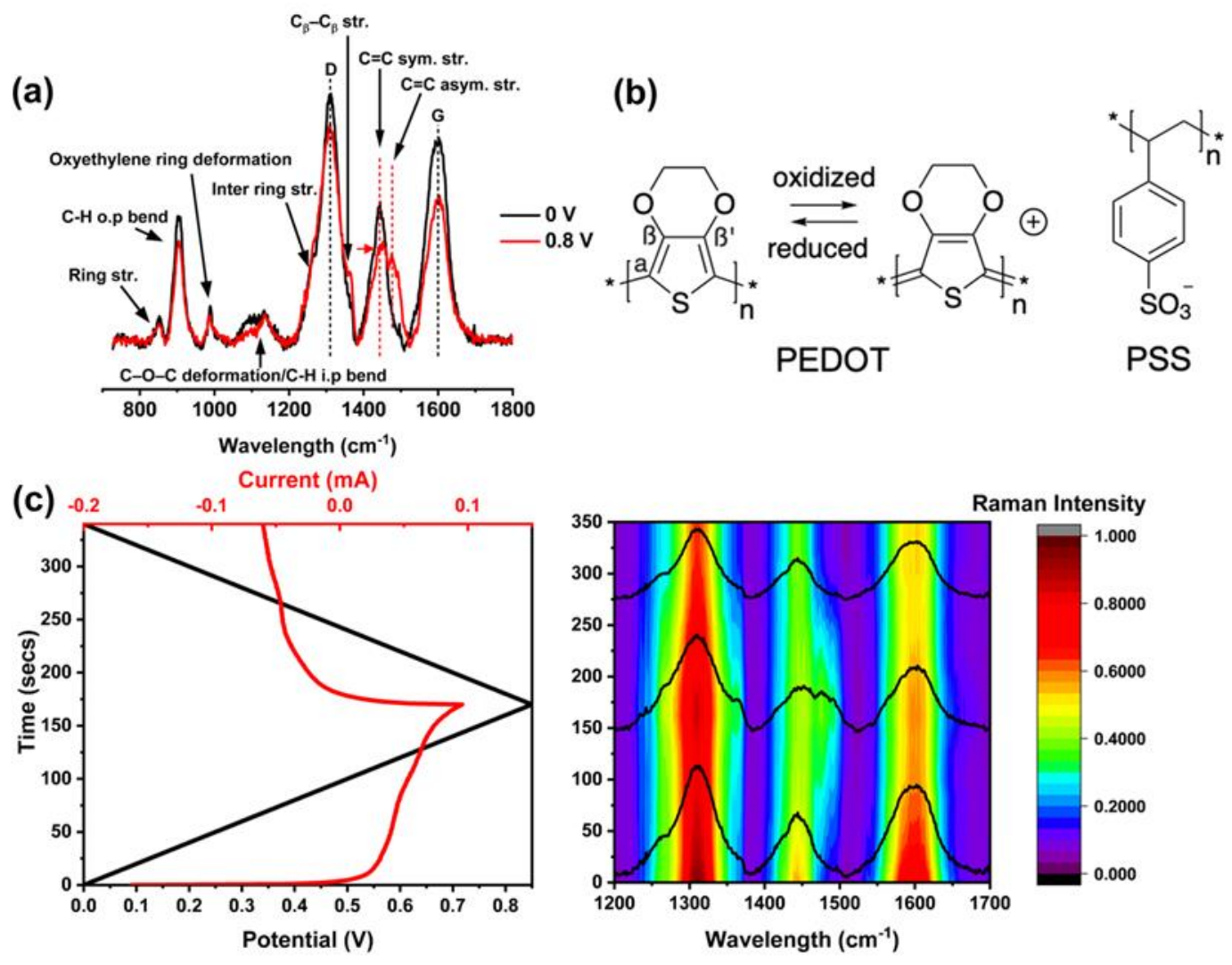


Fig. 9 (a) Raman spectra for the surface of a positive electrode on $\mu$-SC[FLG(NH $\mathrm{NH}_{3}$-MWCNT(Acid)] at 0 and 0.8 V. (b) Chemical structure of PEDOT/PSS. (c) In-situ Raman spectra for a cycling device $\mu$ -

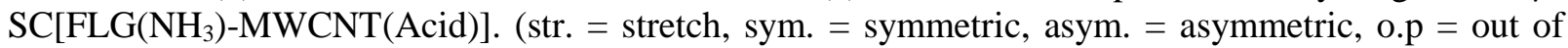
plane, i.p $=$ in plane).

The $\mu$-SC[FLG(NH $\mathrm{NH}_{3}$-MWCNT(Acid)] device was cycled at $5 \mathrm{mV} \mathrm{s}^{-1}$ whilst in-situ Raman microscopy was carried out on the surface of a positive finger of the interdigitated electrodes. Spectra were averaged over 5 repeated charge-discharge cycles between 0 and $0.85 \mathrm{~V} .{ }^{31,32}$ The peak wavelengths are reported here as averages of the 5 replicate spectra. In Fig. 9a, the uncharged Raman shift pattern (black line) shows peaks typically observed with carbon nanomaterials; this is expected as they constitute $80 \%$ of the film composition. Features include the D band $\left(1311 \pm 0.4 \mathrm{~cm}^{-1}\right)$ and $\mathrm{G}$ band $\left(1597 \pm 0.8 \mathrm{~cm}^{-1}\right)$. The PEDOT/PSS component in its reduced state $(0 \mathrm{~V})$ shows characteristic bands for $\mathrm{C}_{\alpha}=\mathrm{C}_{\beta}$ stretching symmetric $\left(1442 \pm 1.0 \mathrm{~cm}^{-1}\right)$ and $\mathrm{C}_{\beta}-\mathrm{C}_{\beta}$, stretching $\left(1359 \pm 2.6 \mathrm{~cm}^{-1}\right)$. The $\mathrm{C}_{\alpha}=\mathrm{C}_{\beta}$ stretching asymmetric band $\left(1487 \pm 0.8 \mathrm{~cm}^{-1}\right)$ appears near the end of the charging cycle at $0.8 \mathrm{~V}$, when the PEDOT is oxidized. The $\mathrm{C}=\mathrm{C}$ stretching antisymmetric band (typically between $1591-1610 \mathrm{~cm}^{-1}$ ) is hidden by the $\mathrm{G}$ band of the FLG and MWCNT. The $C_{\alpha}=C_{\beta}$ stretching symmetric band shifts right slightly, from $1442 \pm 1.0 \mathrm{~cm}^{-1}$ to $1447 \pm 0.7 \mathrm{~cm}^{-1}$ when PEDOT is fully doped at the end of the charging cycle $(0.8 \mathrm{~V})$. The instrument has a resolution of $1.0 \mathrm{~cm}^{-1}$, so this is significant and suggests the PEDOT/PSS is being oxidized during the charging process and interacting with dopant PSS ions. ${ }^{33,34}$ The PEDOT C-C inter ring stretching band at $1259 \pm 1.3 \mathrm{~cm}^{-1}$ shifts to $1264 \pm 2.7 \mathrm{~cm}^{-1}$ with an associated increase in area. The broad band at 1116 $\pm 3.8 \mathrm{~cm}^{-1}$ shifts to a narrow peak $\left(1132 \pm 1.7 \mathrm{~cm}^{-1}\right)$ with a comparable sized area and this is attributed to the PEDOT C-H bending in-plane. When the potential is returned to $0 \mathrm{~V}$, the changes are fully reversible (Fig. 9c). These changes show how PEDOT/PSS in the composite film is undergoing pseudo-capacitive changes during cycling. However, the CV curves of this device (Fig. 7b) show a dominance of electric double layer capacitive-like response, which is expected with high concentrations of FLG and MWCNT, and so the PEDOT/PSS redox reactions are not dominant. The absence of significant changes to the D and G peaks (FLG and MWCNT) during cycling indicates that the material is highly reversible, suggesting a high level of stability.

\section{Conclusion}

The FLG and MWCNT materials were surface functionalized by plasma treatment and these changes were quantified by elemental microanalysis, XPS, zeta-potential measurements and acid-base titrations. The surface functionalities have an impact on the interaction between the FLG and MWCNT materials in composites by electrochemical testing in $\mu$-SC devices. The surface area of the FLG (physical) is suited to the application according to theoretical calculations but the changes made to the surface by plasma treatment show that in addition the electrochemical activated surface area is well-matched to these devices. This means there is greater utilization of these areas and a higher specific capacitance can be achieved, as seen when $\mu$-SC[FLG(NH$)$-MWCNT(Acid)] is studied. The optimal plasma treatment in terms of capacitive performance is obtained with ammonia gas plasma on FLG and acid plasma on MWCNT. These treatments show low levels of functionalization, but these small changes can increase specific capacitance values by up to 4 -fold.

\section{Acknowledgements}

This work was financially supported by the EPSRC (EngD Grant Number 1516481) and by Haydale Ltd. The in-situ Raman microscopy was made possible by the EPSRC grant, EP/M022749/1 (High Spec Raman Spectrometer Regional Facility). The following grants supported a research visit by Emily Smith to the University of Wollongong: the University of Surrey UGPN travel fund, the STFC Futures Early Career Award and the Royal Society of Chemistry Early Career Researcher Mobility Grant.

\section{Conflicts of interest}

There are no conflicts of interest. 


\section{References}

1 D. A. Dikin, S. Stankovich, E. J. Zimney, R. D. Piner, G. H. B. Dommett, G. Evmenenko, S. T. Nguyen and R. S. Ruoff, Nature, 2007, 448, 457-460.

2 Y. Zhu, S. Murali, M. D. Stoller, K. J. Ganesh, W. Cai, P. J. Ferreira, A. Pirkle, R. M. Wallace, K. A. Cychosz, M. Thommes, S. Dong, E. A. Stach and R. S. Ruoff, Science, 2011, 332, 1537-1547.

3 Y. Liu, B. Weng, Q. Xu, Y. Hou, C. Zhao, S. Beirne, K. Shu, R. Jalili, G. G. Wallace, J. M. Razal and J. Chen, Adv. Mater. Technol., 2016, 1, 1600166.

4 S. H. Aboutalebi, A. T. Chidembo, M. Salari, K. Konstantinov, D. Wexler, H. K. Liu and S. X. Dou, Energy Environ. Sci., 2011, 4, 1855.

5 J. Lin, C. Zhang, Z. Yan, Y. Zhu, Z. Peng, R. H. Hauge, D. Natelson and J. M. Tour, Nano Lett., 2013, 13, 72-78.

6 H. R. Byon, S. W. Lee, S. Chen, P. T. Hammond and Y. Shao-Horn, Carbon, 2011, 49, 457467.

7 J. H. Kim, K. W. Nam, S. B. Ma and K. B. Kim, Carbon, 2006, 44, 1963-1968.

$8 \quad$ M. Beidaghi and C. Wang, Adv. Funct. Mater., 2012, 22, 4501-4510.

9 L. Lai, H. Yang, L. Wang, B. K. Teh, J. Zhong, H. Chou, L. Chen, W. Chen, Z. Shen, R. S. Ruoff and J. Lin, ACS Nano, 2012, 6, 5941-5951.

10 Y. Lin, C. Lin and P. Chiu, Appl. Phys. Lett., 2010, 96, 133110.

11 M. Mohai and I. Bertóti, Surf. Interface Anal., 2016, 48, 461-464.

12 J. Li, C. Chen, J. Wei, J. Li and X. Wang, J. Phys. Chem. C, 2014, 118, 28440-28447.

13 A. V Dolbin, V. B. Esel'son, V. G. Gavrilko, N. A. Vinnikov, R. M. Basnukaeva, M. V Khlistuck, W. K. Maser and A. M. Benito, J. Nano- Electron. Phys., 2015, 7, 02008.

14 H. M. Jeong, J. W. Lee, W. H. Shin, Y. J. Choi, H. J. Shin, J. K. Kang and J. W. Choi, Nano Lett., 2011, 11, 2472-2477.

15 M. F. El-Kady and R. B. Kaner, Nat. Commun., 2013, 4, 1475-1479.

16 A. Basu, K. Roy, N. Sharma, S. Nandi, R. Vaidhyanathan, S. Rane, C. Rode and S. Ogale, ACS Appl. Mater. Interfaces, 2016, 8, 31841-31848.

17 Z. S. Wu, K. Parvez, X. Feng and K. Müllen, J. Mater. Chem. A, 2014, 2, 8288-8293.

18 M. F. El-Kady, V. Strong, S. Dubin and R. B. Kaner, Science, 2012, 335, 1326-1330.

19 S. Kwon, Y. Yoon, J. Ahn, H. Lim, G. Kim, J. H. Kim, K. B. Choi and J. J. Lee, Carbon, 2018, 137, 136-145.

20 S. Kwon, D. Jung, H. Lim, G. Kim, K. B. Choi and J. Lee, Appl. Phys. Lett., 2017, 111, 143903.

21 M. Beidaghi and Y. Gogotsi, Energy Environ. Sci., 2014, 7, 867-884.

22 X. Mao, J. Xu, X. He, W. Yang, Y. Yang, L. Xu, Y. Zhao and Y. Zhou, Appl. Surf. Sci., 2018, 435, $1228-1236$.

23 J. J. Yoo, K. Balakrishnan, J. Huang, V. Meunier, B. G. Sumpter, A. Srivastava, M. Conway, A. L. Mohana Reddy, J. Yu, R. Vajtai and P. M. Ajayan, Nano Lett., 2011, 11, 1423-1427. 
24 A. Felten, C. Bittencourt, J. J. Pireaux, G. Van Lier and J. C. Charlier, J. Appl. Phys., 2005, 98, 074308.

25 I. Bertóti, M. Mohai and K. László, Carbon, 2015, 84, 185-196.

26 D. Yang, A. Velamakanni, G. Bozoklu, S. Park, M. Stoller, R. D. Piner, S. Stankovich, I. Jung, D. A. Field, C. A. Ventrice and R. S. Ruoff, Carbon, 2009, 47, 145-152.

27 R. J. Hunter, Zeta Potential in Colloid Science, Elsevier, 1981.

28 B. Konkena and S. Vasudevan, J. Phys. Chem. Lett., 2012, 3, 867-872.

29 S S Dukhin, Surface and Colloid Science, J. Wiley \& Sons, New York, 1974.

30 W. Liu, C. Lu, X. Wang, R. Y. Tay and K. Tay, ACS Nano, 2015, 9, 1528-1542.

31 T. Lindfors, Z. A. Boeva and R.-M. Latonen, RSC Adv., 2014, 4, 25279-25286.

32 D. Yoo, J. Kim, S. H. Lee, W. Cho, H. H. Choi, F. S. Kim and J. H. Kim, J. Mater. Chem. A, $2015,3,6526-6533$.

33 W. W. Chiu, J. Travaš-Sejdić, R. P. Cooney and G. A. Bowmaker, J. Raman Spectrosc., 2006, 37, 1354-1361.

34 M. Stavytska-barba and A. M. Kelley, J. Phys. Chem. C, 2010, 114, 6822-6830. 